\title{
Postanthesis Flower and Fruit Abscission in 'Manzanillo' Olive
}

\author{
H.F. Rapoport and L. Rallo \\ Departamento de Agronomía, Universidad de Córdoba, Apartado 3048, Córdoba, Spain \\ Additional index words. Olea europea, anatomy, fertilization, fruit set, ovary
}

\begin{abstract}
The dramatic postanthesis flower and fruit abscission in olive was found to consist of two distinct but overlapping phases for ovaries following the abscission of imperfect flowers. Imperfect flower abscission peaked 8 days after full bloom (FB), while perfect flower and fruit abscission was greatest between 13 to 15 days after FB. Ovary abscission, expressed as percent ovaries abscising per day (relative abscission rate), peaked 15 and 21 days after FB. The first ovary abscission phase includes fertilized and unfertilized ovaries. The second phase occurs once early fruit growth is in progress, suggesting a possible role for substrate competition.
\end{abstract}

Final fruit count in olive is determined in a brief, intense period of flower and fruit abscission the first 5 to 7 weeks following full bloom (Lavee, 1986; Rallo and Fernández-Escobar, 1985; Rallo et al., 1981). Abscission of imperfect flowers (Uriu, 1960), unfertilized perfect flowers, and then fertilized ovaries or fruits occurs in rapid succession; thus, these stages have been difficult to separate experimentally. Examination of the phenomena involved in postanthesis abscission is further complicated by the large proportion of ovaries that abscise $(95 \%$ to $98 \%$ ) (Lavee, 1986) and by the variability among flowers in the timing of anthesis and subsequent floral development.

The increment in ovary size 12 to 15 days after FB (Rallo and Fernández-Escobar, 1985) implies that most shedding after that time is due to competition among fertilized ovaries. Without observations of fertilization, however, it is unclear how early and in what proportion fertilized ovaries are abscised, and, therefore, to what extent the lack of fertilization is a factor in flower abscission.

Examination of the factors involved in postanthesis abscission in olive first requires a precise characterization of the phases that occur. In the following study, flower and fruit abscission were monitored daily, growth of retained and abscised ovaries was compared, and fertilization and embryo sac development was examined in abscised ovaries.

\section{Materials and Methods}

Five 7-year-old 'Manzanillo' trees were used at the Alameda del Obispo experimental farm in Córdoba, Spain. Just before bloom, uniform unbranched flowering shoots with 12 to 20 inflorescence-bearing nodes were selected. FB was determined as the day on which $>50 \%$ of the flowers were open on at least $70 \%$ of the inflorescences per shoot on $50 \%$ or more of the selected shoots. The number of imperfect flowers and perfect flowers or fruits per node on five shoots per tree was recorded daily from 1 to 18 days and at 20, 22, 24, 31, and 37 days after FB. On the same dates, after abscission of perfect flowers began, additional selected flowering shoots were used to provide ovaries for anatomical analysis. These shoots were shaken into plastic bags to separate "persisting" (those which remained on the shoot) and "abscised" ovaries (collected in the bags). The two groups of ovaries were counted and weighed. The abscised

Received for publication 3 Apr. 1990. We gratefully acknowledge support by CAICYT PA 86/0092, Ministry of Education and Science, Madrid, Spain. The cost of publishing this paper was defrayed in part by the payment of page charges. Under postal regulations, this paper therefore must be hereby marked advertisement solely to indicate this fact. ovaries were then fixed in 2 formalin : 1 acetic acid : $1760 \%$ ethanol (by volume), embedded in paraffin, sectioned at $12 \mu \mathrm{m}$, and stained in tannic acid, iron chloride, safranin, and fast green (Jensen, 1962) for anatomical observations.

Data were expressed on the basis of total flowers (imperfect and perfect) or total perfect flowers at FB. Relative abscission rate was calculated as described by Zucconi et al. (1978). For the sampled (shaken) branches, it was assumed that the abscised ovaries would fall the following day; relative abscission rate was estimated as the ratio of abscised to total (retained $+a b$ scised) ovaries. Means and standard errors were calculated on a per-tree basis.

\section{Results}

Abscission patterns. Cumulative abscission (Fig. 1A) was continuous from $\mathrm{FB}$ until $\approx 25$ days after FB. Abscission of imperfect flowers (Fig. 1B) began soon after FB, reached a peak 8 days after $\mathrm{FB}(\mathrm{FB}+8)$, and continued until $\mathrm{FB}+15$.

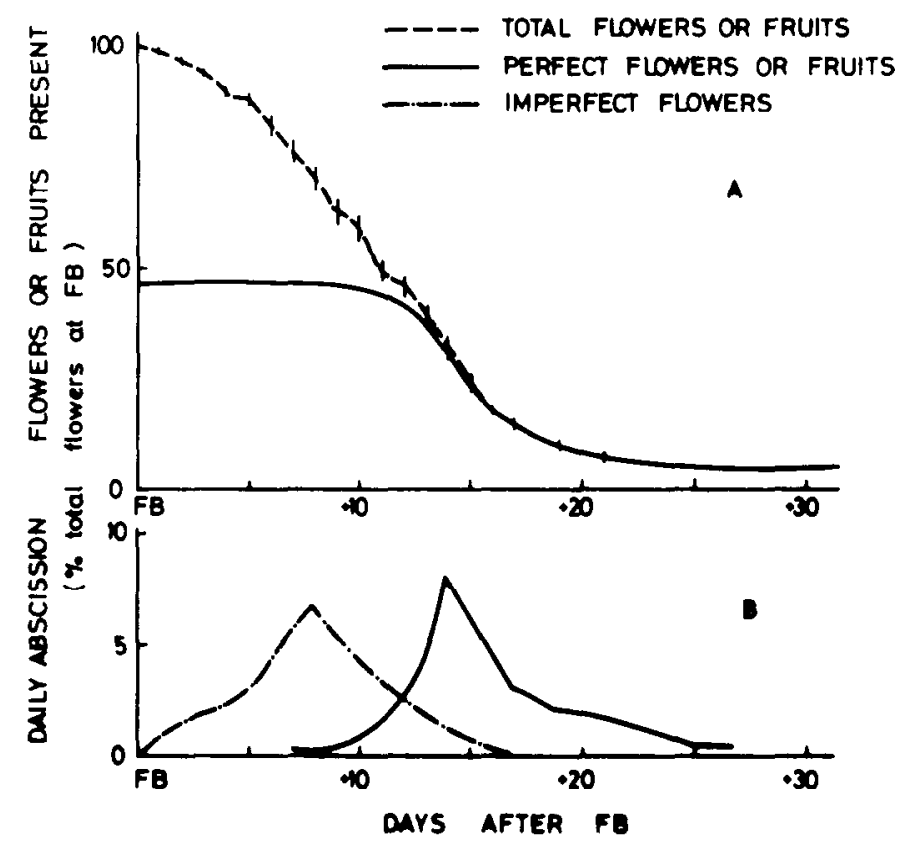

Fig. 1. Abscission patterns for olive flowers and fruits following full bloom (FB). The data are expressed as percentages of the total number of flowers present at FB. (A) Total flowers and/or fruits present. Bars represent \pm SE per tree for total flowers; \pm SE for perfect flowers is shown in Fig. 2. (B) Daily abscission rate. Data derived from (A). 
Abscission of perfect flowers or fruits (Fig. 1B) occurred largely from $\mathrm{FB}+10$ to $\mathrm{FB}+25$ days, with the greatest abscission occurring between 13 and 15 days after FB.

The abscission patterns presented in Fig. 1 were calculated on the basis of total flower count at FB, whereas the data in Fig. 2 were calculated relative to the number of perfect flowers at FB. As demonstrated in Fig. 1, abscission of perfect flowers or fruits was concentrated between $\mathrm{FB}+10$ and $\mathrm{FB}+15$; however, the greater detail obtained by using the number of perfect flowers at $\mathrm{FB}$ as a basis for calculation reveals a rapid increase in abscission $(\mathrm{FB}+10-\mathrm{FB}+15)$ and a more extended period $(\mathrm{FB}+16-\mathrm{FB}+25)$ when abscission rate declined (Fig. 2 A and B).

Relative abscission rate (Fig. 2C) occurred in two phases: the first had a steep narrow peak with maximum relative abscission between $\mathrm{FB}+13$ and $\mathrm{FB}+16$. That was followed by a second low and broad peak with a maximum at 21 days after FB. Relative abscission rate for the sampled (shaken) branches shows the same bimodality, although displaced, as that of the control branches (Fig. 2C).

Fruit growth. Fresh weight of retained ovaries increased grad-
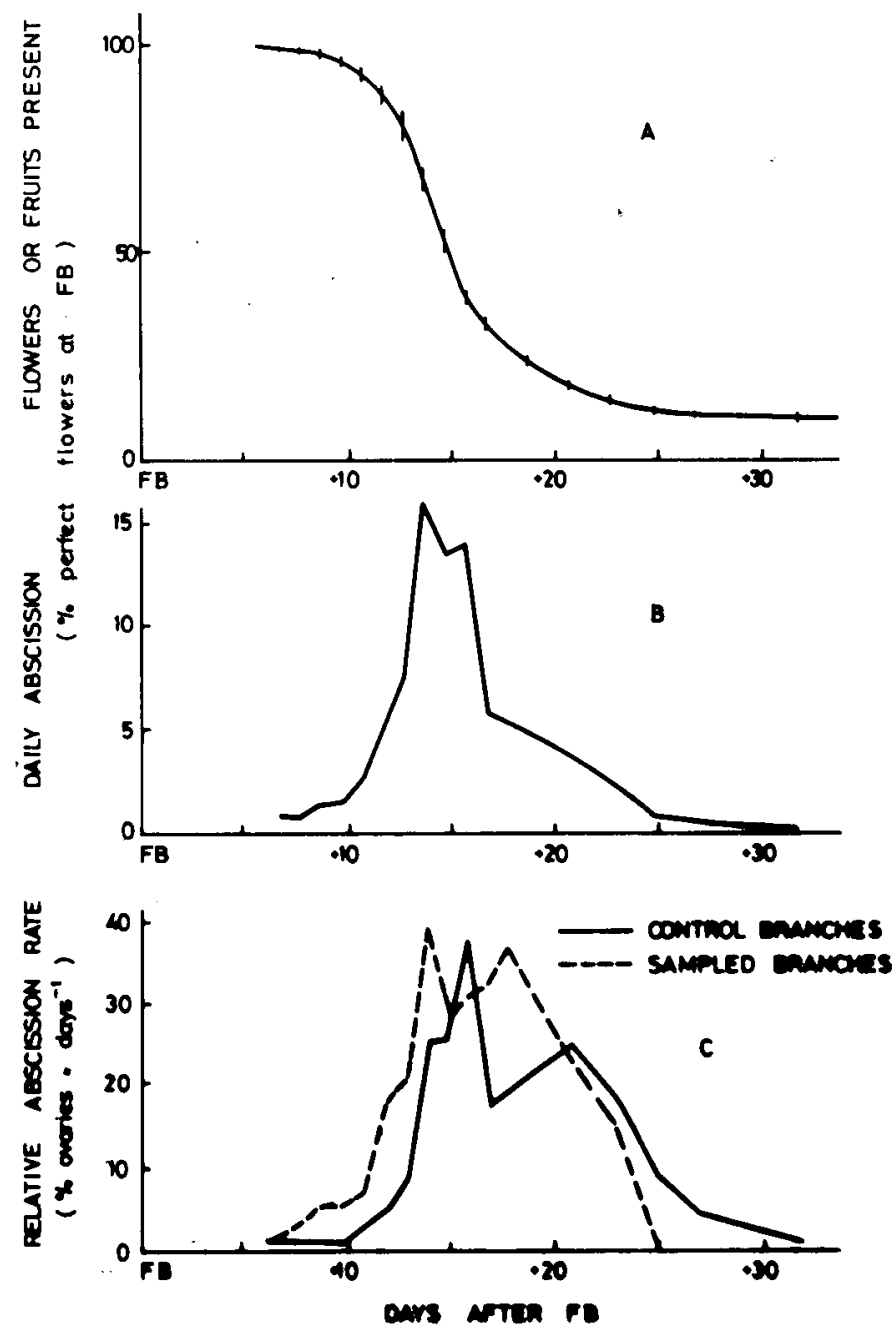

Fig. 2. Abscission patterns for perfect flowers or fruits following full bloom (FB). The data are expressed as percentages of the number of perfect flowers present at FB. (A) Flowers or fruits present. Bars represent \pm SE per tree. (B) Daily abscission rate. (C) Relative abscission rate. Data for (B) and (C) control branches derived from (A) (see text). ually from $\mathrm{FB}+10$ to $\mathrm{FB}+14$, and rapidly thereafter (Fig. 3 ). Abscised ovaries showed a similar pattern but with a lag of a few days: fresh weight increased gradually from about FB + 14 to $\mathrm{FB}+18$ and then became more rapid. At all times, mean fresh weight for abscised ovaries was less than that for retained ovaries.

Anatomical observations. In contrast to the two polar nuclei located in the central zone of the mature, unfertilized embryo sac (Fig. 4A), the best and often only indication of fertilization was the presence of three or more endosperm nuclei (Fig. 4B). Although the olive endosperm is cellular, cell walls were difficult to distinguish in the early phases. Germinated pollen grains were present on the stigmatic surface, but no pollen tubes were observed in stigma, style, or ovary tissues. Often, the embryo sac had a disorganized, degenerate appearance (Fig. 4C), making observations difficult. Due to the loss of ovules during sectioning and difficulties in microscopic interpretation, fertilization could only be evaluated in about half of the ovaries (Table 1). In those ovaries, the proportion of abscised ovaries that were fertilized increased from $22 \%$ at $\mathrm{FB}+8$ to $62 \%$ at $\mathrm{FB}+18$.

Undeveloped embryo sacs (Fig. 4D), consisting of a small cavity at the end of a long channel open at the micropyle, occur regularly in olive ovules (Extremera, 1985; Rallo et al., 1981).

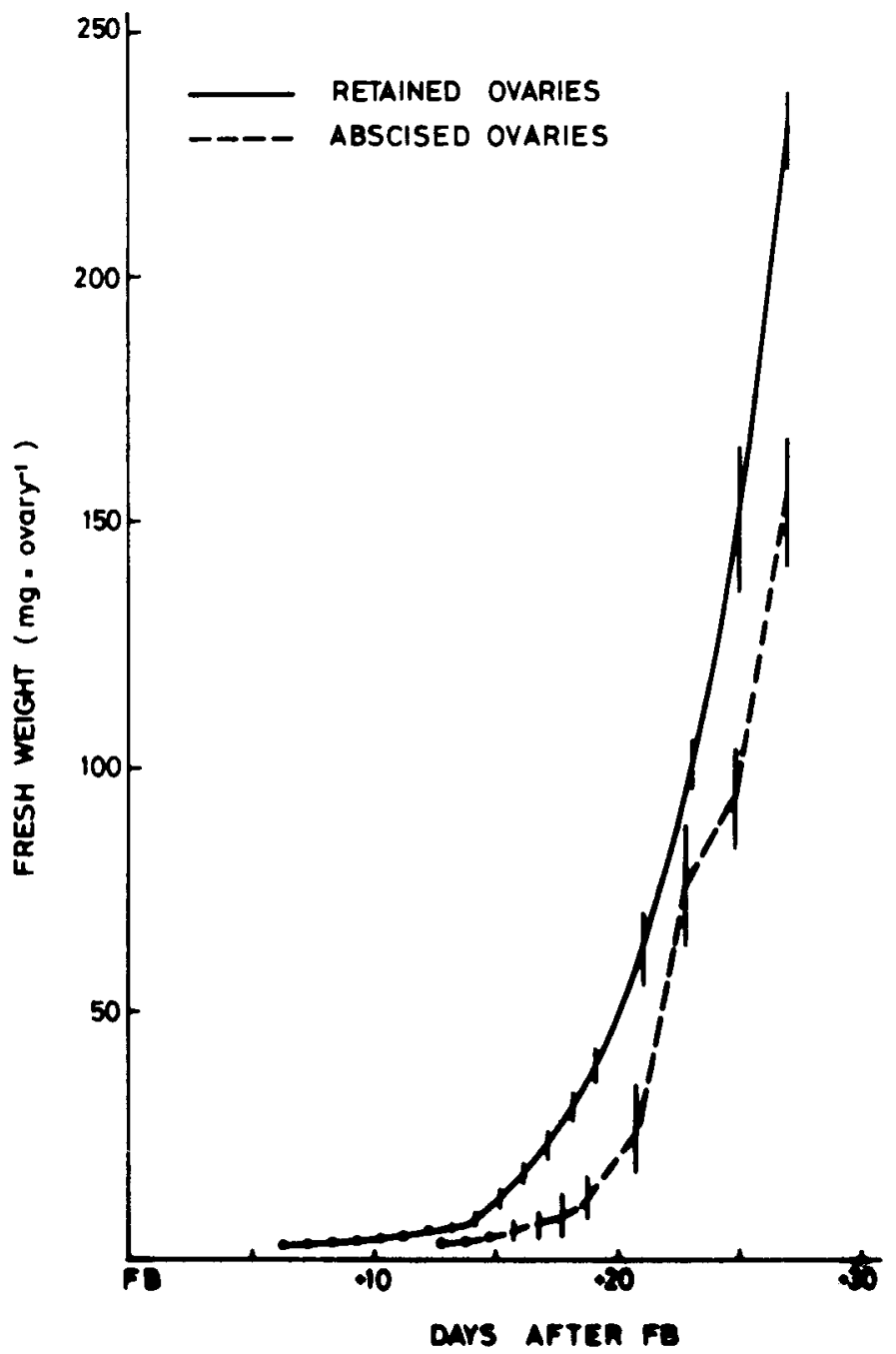

Fig. 3. Ovary growth following full bloom. The data were calculat from total weight of daily samples. Abscised ovaries were obtained by shaking (see text). Bars represent \pm SE per tree. 


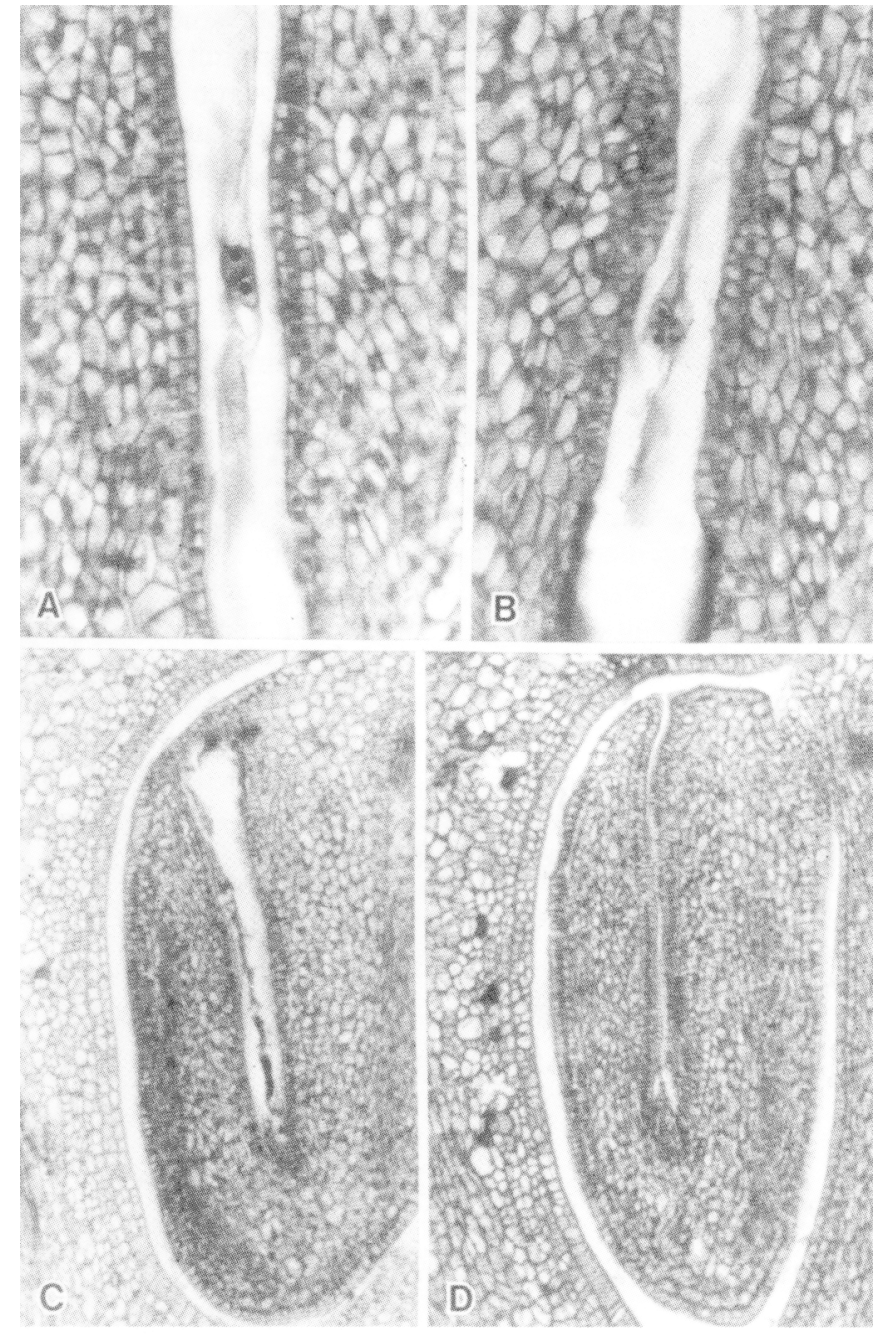

Fig. 4. Structural aspects of ovule development following anthesis. Longitudinal sections. (A) Mature, unfertilized embryo sac. View of the two centrally positioned polar nuclei.(B) Early stage of endosperm development with three nuclei visible. (C) Embryo sac with disorganized, degenerate contents. (D) Undeveloped embryo sac consisting of a long channel open at the micropyle. (A) and (B) $\times 256$. (C) 2 nd (D) $\times 102$.

Table 1. Estimated fertilization in olive ovaries.

\begin{tabular}{|c|c|c|c|c|}
\hline \multirow{2}{*}{$\begin{array}{l}\text { Days after } \\
\text { full bloom }\end{array}$} & \multirow{2}{*}{$\begin{array}{c}\text { Total ovaries } \\
\text { examined }\end{array}$} & \multicolumn{2}{|c|}{$\begin{array}{l}\text { Ovaries used } \\
\text { to evaluate } \\
\text { fertilization }^{2}\end{array}$} & \multirow{2}{*}{$\begin{array}{c}\text { Fertilized } \\
\text { ovaries }^{\mathrm{y}} \\
(\%) \\
\end{array}$} \\
\hline & & (no.) & $(\%)$ & \\
\hline 8 & 21 & 9 & 43 & 22 \\
\hline 10 & 24 & 15 & 62 & 32 \\
\hline 12 & 89 & 62 & 70 & 44 \\
\hline 14 & 60 & 36 & 60 & 43 \\
\hline 16 & 81 & 48 & 59 & 55 \\
\hline 18 & 67 & 43 & 64 & 62 \\
\hline
\end{tabular}

${ }^{7}$ Fertilization could not be evaluated in all ovaries due to ovule loss in sectioning, interpretation difficulties, and the need to observe all four ovules. See text for further explanation.

${ }^{y}$ Based on the ovaries in which fertilization could be evaluated.

On all sampling dates, undeveloped embryo sacs were present in about one-third of the ovules, with a slight increase in their occurrence at 16 and 18 days after FB (Table 2).
Table 2. Incidence of undeveloped embryo sac in olive ovules.

\begin{tabular}{lccc}
\hline \hline \multirow{2}{*}{$\begin{array}{c}\text { Days after } \\
\text { full bloom }\end{array}$} & $\begin{array}{c}\text { Ovules } \\
\text { observed }\end{array}$ & \multicolumn{2}{c}{$\begin{array}{c}\text { Ovules with undeveloped } \\
\text { embryo sac }\end{array}$} \\
\cline { 3 - 4 } & (no.) & (no.) & $(\%)$ \\
\hline 8 & 60 & 18 & 30 \\
10 & 90 & 30 & 33 \\
12 & 269 & 72 & 27 \\
14 & 192 & 51 & 27 \\
16 & 265 & 101 & 38 \\
18 & 217 & 84 & 39 \\
\hline
\end{tabular}

\section{Discussion}

As has been previously demonstrated for olive (Lavee, 1986; Rallo and Fernández-Escobar, 1985), abscission occurred in a brief, intense period following FB (Figs. 1 and 2). While abscission of imperfect flowers clearly precedes that of perfect flowers and fruits, there is also a distinct period of overlap (Fig. 1B). Thus, any observations during that time must include the separation of the two kinds of flowers. Abscission of perfect flowers did not commence until FB +8 days (Figs. 1 and 2), indicating that measurements of that phenomenon may safely begin the week following FB.

The bimodal curve for relative abscission rate (Fig. 2C) was found in 3 years (unpublished data). That pattern suggests the occurrence of two overlapping abscission phases for ovaries. The first of these would include the abscission of unfertilized flowers, triggered by pollination, fertilization, and/or the onset of ovary enlargement in adjacent flowers. The presence of fertilized ovaries in the abscised populations as early as FB +8 (Table 1) indicates that fertilized as well as unfertilized ovaries are lost in the first abscission phase. Although fertilized, these ovaries might not compete favorably with more advanced, i.e., earlier fertilized, flowers.

It is likely-that the second abscission phase, indicated by the relative abscission rate (Fig. 2C), represents abscission due to substrate competition between growing fruits. That phase coincides with the period of rapid (exponential) expansion for retained ovaries (Fig. 3). The ovaries that abscise also start enlarging, and by $\mathrm{FB}+20$, their growth becomes rapid as well (Fig. 3). Overlap between the two phases is indicated by the presence of unfertilized ovaries in the abscised group as late as $\mathrm{FB}+18$ (Table 1).

Ovaries about to abscise were consistently smaller than retained ovaries (Fig. 3). In apple (Weinbaum and Simmons, 1974), avocado (Sedgley, 1980), orange (Zucconi et al., 1978), and peach (Arbeloa, 1986; Harrold, 1935), the smaller ovary size in the population destined to abscise has been interpreted as being due to a decline in growth before abscission. Zucconi et al. (1978) were able to demonstrate by tagging and monitoring the growth of individual orange fruits during the abscission period, that growth rate declined. The apparent embryo sac degeneration observed in our material (Fig. 4C) could have been caused by the cessation of development before abscission. An alternative explanation for the smaller size of abscising ovaries (Fig. 3) might be that the less-developed fruits are those that abscise.

Sampled branches were shaken into plastic bags to obtain the abscised ovaries. It was assumed that the ovaries removed by shaking were those ovaries that were about to abscise and would have abscised naturally during the following day(s). The similar values and changes of relative abscission rates for the control and shaken branches (Fig. 2C) support the validity of the shak- 
ing method. The displacement of the curve for sampled branches (Fig. 2C) agrees with the assumption that abscission was accelerated by shaking.

Anatomical observation of fertilization in the abscised ovaries was difficult. The best criterion was the onset of endosperm development, indicated by the presence of three or more nuclei in the central zone of the embryo sac (Fig. 4B). Altamura Betti et al. (1982) were able to differentiate between the polar nuclei and the two-cell stage of endosperm development, but in our material, either no two-celled endosperms were present or this stage appeared very similar to the two polar nuclei in their mature, juxtaposed position (Fig. 4A) (Extremera et al., 1988; King, 1938). Pollen tubes in olive pistils have been reported by King (1938) and Bradley and Griggs (1963), but were not observed in our preparations. The disorganized, degenerate appearance of many embryo sacs (Fig. 4D) obscured many anatomical details indicative of fertilization. Sedgley (1980) described similar problems in the interpretation of fertilization in abscised avocado fruits due to dark staining and reduced tissue definition.

The analysis of fertilization was complicated by the need to consider all four ovules to determine whether a particular ovary was fertilized. In many ovaries, one or more ovules could not be evaluated either because of loss during sectioning or difficulties in interpretation. Loss of ovules during sectioning apparently occurred because these are small, hard, and relatively unsupported in the paraffin-filled locule. It may also be possible that abscission-related degeneration contributed to hardening of the ovules. Ovules with unformed embryo sacs (Fig. 4D) are characteristic of the nonfruiting olive cultivar Swan Hill (Extremera, 1985; Rallo et al., 1981). They also occur regularly, although less frequently, in fruiting olive cultivars (Bradley and Griggs, 1963; Extremera, 1985; Rallo et al., 1981). Their presence could be a factor in perfect flower abscission, since ovules without developed embryo sacs cannot be fertilized. While further experiments are necessary to test this hypothesis, our studies indicated relatively constant proportions of those ovules (Table 2), yet increased fertilization(Table 1) during the abscission period. The slight increase at 16 and 18 days after FB (Table
2) could be due to an increase in undeveloped embryo sacs in late-forming ovules or to the similar appearance of unfertilized embryo sacs that close as a part of senescence.

\section{Literature Cited}

Altamura Betti, M.M., G. Pasqua, and G. Mazzolani. 1982. Embryogenesis in Olea europea L. Annali di Botanica 40:141-152.

Arbeloa, A. 1986. Estudio de la biología floral y frutificación en melocotonero (Prunus persica (L.) Batsch). Thesis, Universidad de Pamplona, Pamplona, Spain.

Bradley, M.V. and W.H. Griggs. 1963. Morphological evidence of incompatibility in Olea europea L. Phytomorphology 13:141-156.

Extremera, G. 1985. Desarrollo del saco embrionario en dos cultivates de olivo (Olea europaea L.). Tesina de licenciatura, Facultad de Ciencias, Univ. de Córdoba, Córdoba, Spain.

Extremera, G., H.F. Rapoport, and L. Rallo. 1988. Caracterización del saco embrionario en olivo (Olea europea L.). Anales JardínBotánico Madrid 45(1):197-211.

Harrold, T.J. 1935. Comparative study of the developing and aborting fruits of Prunus persica. Bot. Gaz. 96:505-520.

Jensen, W.A. 1962. Botanical histochemistry. W.H. Freeman, San Francisco.

King, J.R. 1938. Morphological development of the fruit of the olive. Hilgardia 11:437-458.

Lavee, S. 1986. Olive, p. 267-276. In: S.P. Monselise (ed.). Handbook of fruit set and development. CRC Press, Boca Raton, Fla.

Rallo, L. and R. Fernández-Escobar. 1985. Influence of cultivar and flower thinning within the inflorescence on competition among olive fruit. J. Amer. Soc. Hort. Sci. 110:303-308.

Rallo, L., G.C. Martin, and S. Lavee. 1981. Relationship between abnormal embryo sac development and fruitfulness in olive. J. Amer. Soc. Hort. Sci. 106:813-817.

Sedgley, M. 1980. Anatomical investigation of abscised avocado flowers and fruitlets. Ann. Bot. 46:771-777.

Uriu, K. 1960. Periods of pistil abortion in the development of the olive flower. Proc. Amer. Soc. Hort. Sci. 73:194-202.

Weinbaum, S.A. and R.K. Simmons. 1974. An ultrastructural evaluation of the relationship of embryo/endospenn abortion to apple fruit abscission during the post-bloom period. J. Amer. Soc. Hort. Sci. 99:311-314.

Zucconi, F., S.P. Monselise, and R. Goren. 1978. Growth-abscission relationships in developing orange fruit. Scientia Hort. 9:137-146. 